\title{
A INFLUÊNCIA DA CONSTRUÇÃO DE PAPEIS SOCIAIS DE GÊNERO NA ESCOLHA PROFISSIONAL
}

\author{
THE INFLUENCE OF GENDER SOCIAL CONSTRUCTION ON PROFESSIONAL \\ CHOICE
}

\author{
Flaviane Izidro Alves de LIMA ${ }^{1}$ \\ Ana Elisa Gambarti Teixeira VOIG ${ }^{2}$ \\ Marianne Ramos FEIJÓ ${ }^{3}$ \\ Mario Lázaro CAMARGO ${ }^{4}$ \\ Hugo Ferrari CARDOSO 5
}

RESUMO: A educação sexista é transmitida dentro e fora das escolas por meio das relações sociais dos indivíduos, o que contribui para que homens e mulheres (re)produzam lugares sociais diferentes a partir da atribuição de papeis sociais de gênero. Esse processo leva a construção de diferentes formas de comportamentos, interesses e escolhas, inclusive, relacionadas ao trabalho. Realizou-se uma revisão bibliográfica, nas bases de dados: portal de periódicos eletrônicos de Psicologia (PePSIC) da Biblioteca Virtual em Saúde - Psicologia (BVS-PSI), Scientific Eletronic Library Online (SCIELO), bem como no banco de teses da Coordenação de Aperfeiçoamento de Pessoal de Nível Superior (CAPES) e nos livros e periódicos catalogados na biblioteca da Universidade Estadual Paulista "Júlio de Mesquita Filho", campus de Bauru, a fim de investigar como a educação, formal e informal, permeada por questões de gênero, influenciam os interesses e escolhas profissionais. Constatou-se a importância da reflexão e da discussão sobre questões de gênero no tocante aos interesses e escolhas profissionais e a consequente produção de novos estudos sobre o tema, já que as desigualdades de gênero vividas na sociedade e, portanto, nas organizações de trabalho, limitam escolhas, relações, o desenvolvimento e, podem prejudicar a saúde das pessoas.

PALAVRAS-CHAVE: Gênero. Escolha profissional. Orientação profissional.

ABSTRACT: Sexist education is transmitted inside and outside of schools through social relations among individuals, which contributes to men and women (re)product different social places from the allocation of social gender roles. That process leads to different forms of construction of behavior, interests and choices, including work-related ones. We conducted a literature review, in this databases: portal of e-journal Psychology (PePSIC) Virtual Health

\footnotetext{
${ }^{1}$ Universidade Estadual Paulista (Unesp), Faculdade de Ciências, Bauru - SP - Brasil. Graduada em Psicologia. E-mail: flavianeizidro@ hotmail.com.

${ }^{2}$ Universidade Estadual Paulista (Unesp), Faculdade de Ciências, Bauru - SP - Brasil. Graduada em Psicologia. E-mail:anaelisagambarti@hotmail.com.

3 Universidade Estadual Paulista (Unesp), Faculdade de Ciências, Bauru - SP - Brasil. Professora do Departamento de Psicologia. E-mail:mariannefeijo@fc.unesp.br.

4 Universidade Estadual Paulista (Unesp), Faculdade de Ciências, Bauru - SP - Brasil. Professor do Departamento de Psicologia. E-mail:mario.camargo@fc.unesp.br.

5 Universidade Estadual Paulista (Unesp), Faculdade de Ciências, Bauru - SP - Brasil. Professor do Departamento de Psicologia. E-mail:hfcardoso@fc.unesp.br.
} 
Library - Psychology (BVS-PSI), Scientific Electronic Library Online (SciELO) and the thesis database of Coordination Higher Level Personnel Training (CAPES) and books and journals cataloged in the library of the Universidade Estadual Paulista "Julio de Mesquita Filho", campus of Bauru, in order to investigate how education, formal and informal, permeated by gender influences the interests and career choices. It was noted the importance of reflection and discussion on gender issues with regard to professional interests and choices and the consequent production of new studies on the subject, since gender inequalities experienced in society, so the labor organizations, limit choices, relationships, development and can harm the health of people.

KEYWORDS: Gender. Professional choice. Professional guidance.

\section{Introdução}

Sabe-se que a escolha profissional pode ser influenciada por fatores étnicos, sociais, econômicos, familiares, pessoais e de gênero. No entanto, o presente artigo, de natureza teórica, objetiva refletir e discutir sobre a influência dos papéis sociais de gênero na escolha profissional (SANTOS, 2005; BOCK, 2006).

Considera-se relevante a discussão do tema no cenário contemporâneo, visto que colocar em pauta as consequências da educação sexista contribui para o desvelamento das diferentes formas de socialização vivenciadas por homens e mulheres ao longo do seu desenvolvimento - e que resultam em distintas tomadas de decisões profissionais (NOGUEIRA, 2001).

Muitos desdobramentos do tema sexismo poderiam ser discutidos no presente artigo já que se acredita que os efeitos negativos produzidos pela educação sexista existirão enquanto as relações entre os indivíduos pautarem-se numa concepção androcêntrica, que coloca o homem no centro de tudo que existe, e enquanto permanecer o silêncio quanto à contribuição das mulheres para a construção do mundo humano e se mantiverem ocultas as normas de conduta que moldam os corpos, os pensamentos e os comportamentos de todos (MORENO, 1999).

Sabe-se que a educação sexista não é facilmente percebida e muitos dos comportamentos atribuídos a homens e mulheres são tomados como naturais e universais, ou seja, decorrentes de diferenças biológicas e presentes em quaisquer culturas. E, sexo biológico e gênero comumente são utilizados como termos sinônimos. A educação sexista não se encontra presente somente nas escolas, mas permeia toda a trama de relações sociais dos indivíduos, bem como a transmissão de conhecimentos (FEIJÓ; MACEDO, 2012). 
Por isso, no presente artigo são abordados os processos de construção de papéis e expectativas de gênero e o processo de atribuição de características e atributos femininos e masculinos e de como tais atributos são socializados e apropriados pelos indivíduos durante o processo de escolarização e relacionados a diversas profissões, originando crenças sobre a existência de profissões femininas e profissões masculinas, culminando em determinados interesses profissionais em detrimento de outros e, por sua vez, em determinadas escolhas em detrimento de outras.

Para iniciar a discussão, julga-se essencial diferenciar o conceito de sexo biológico do conceito de gênero (PRAUN, 2011). Isso porque o conceito de sexo biológico diz respeito às características físicas e anatômicas que diferenciam mulheres e homens. Estes últimos possuem um aparelho reprodutor dotado de testículos, epidídimo, ducto deferente, vesículas seminais, próstata, glândulas bulbouretrais, escroto e pênis. Enquanto as mulheres possuem um aparelho reprodutor dotado de ovários, tubas uterinas, útero, vagina e vulva.

No tocante ao conceito de gênero, este envolve um conjunto de representações culturais, valores e atribuições sociais direcionadas a cada gênero, o masculino e o feminino. São distinções de caráter social que, na maioria das vezes, baseiam-se no corpo. Como escreveu Louro (2012, p. 49):

[...] os corpos, como bem sabemos, estão longe de ser uma evidência segura das identidades! Não apenas porque eles se transformam pelas inúmeras alterações que o sujeito e as sociedades experimentam, mas também porque as intervenções que nele fazemos são, hoje, provavelmente mais amplas e radicais do que em outras épocas. [...] Tudo isso torna cada vez mais problemática a pretensão de tomá-los como estáveis e definidos.

Além disso, vale dizer que o conceito de gênero envolve as relações sociais estabelecidas entre os indivíduos, nas e pelas quais homens e mulheres são educados de maneiras diferenciadas, levando-os a assumirem e exercerem diferentes papéis sociais e atividades laborais na sociedade. Nessa esteira, tem-se que:

[...] uma noção singular de gênero e sexualidade vem sustentando currículos e práticas de nossas escolas. Mesmo que se admita que existem muitas formas de viver os gêneros e a sexualidade, é consenso que a instituição escolar tem obrigação de nortear suas ações por um padrão: haveria apenas um modo adequado, legítimo, normal de masculinidade e de feminilidade e uma única forma sadia e normal de sexualidade, a heterossexualidade; afastar-se desse padrão significa buscar o desvio, sair do centro, tornar-se excêntrico. (LOURO, 2012, p. 43-44). 
Mostra-se, assim, “[...] indispensável que reconheçamos que a escola não apenas reproduz ou reflete as concepções de gênero e sexualidade que circulam na sociedade, mas que ela própria as produz.” (FURLANI apud LOURO, 2012, p.69). Julga-se que a diferenciação na educação oferecida para homens e mulheres repercute em todas as esferas da vida dos sujeitos, o que implica dizer que repercute também, como já dito anteriormente, sobre a esfera do trabalho e da escolha profissional e a socialização dos que se expressam de forma que fuja aos padrões heteronormativos.

A atribuição aos indivíduos do gênero masculino e feminino de maneira correspondente ao sexo biológico é efetuada antes mesmo do nascimento, constituindo-se a família como a primeira instância socializadora dos indivíduos, sendo "[...] fortemente domesticadora para ambos os sexos. Impossível, no entanto, fugir ao fato de que o modelo educativo feminino é muito mais artificial, exigindo e resultando maior grau de repressão e subordinação" (WHITAKER, 1995, p.36). As meninas aprendem a se sentar de pernas fechadas, os meninos a se sujar, as meninas aprendem que são meigas, carinhosas e princesas e os meninos, que são espoletas, durões e garanhões.

Esse processo de ensino e aprendizagem de como ser menino e menina é definitivamente reforçado pela escola, que pode ser apontada como a grande (re)produtora, como instituição normativa que é, em todos os seus níveis, do sexismo e dos papéis de gênero, do que é socialmente considerado adequado e possível para um homem e para uma mulher, os modos adequados e possíveis de ser, agir, pensar, decidir, enfim, viver. Pode-se afirmar que "[...] a escola é uma caricatura da sociedade. Por ela passam, como não passam por nenhum outro lugar, limitadas por diminutivos, todas as ideias que uma sociedade quer transmitir para conservar, tudo aquilo que se acredita ou quer que se acredite" (MORENO, 1999, p.12). E, nota-se que:

[...] o currículo, as disciplinas, as normas regimentais, as formas de avaliação, os materiais didáticos, a linguagem, constituem-se em instâncias que refletem e produzem as desigualdades de gênero, de sexo, de raça, etc., e podem incentivar o preconceito, a discriminação, o sexismo. (FURLANI apud LOURO, 2012, p. 69).

Sabe-se que os seres humanos, homens e mulheres, diferentemente das demais espécies de seres vivos, não nascem destinados a executarem uma coisa ou outra. É a sociedade, na verdade, que organiza e regulamenta o tempo, o espaço e os movimentos de todos, que treina, molda e marca os corpos dos indivíduos com as formas masculinas e femininas vigentes (BORDO, 1997). É a sociedade que hierarquiza o masculino e o feminino 
e lhes atribui destinos sociais diferentes e perspectivas de vida desiguais. (LOURO; FELIPE; GOELLNER, 2010).

Daí a importância de que os indivíduos sejam esclarecidos a respeito da influência da construção dos papéis de gênero nas escolhas profissionais, colocando-os como mais um fator oculto que precisa ser desvelado. Isso porque a referida construção é internalizada e naturalizada de modo tão bem-sucedido (MARTINS, 2011) que os indivíduos não conseguem identificar tudo o que existiu de influência ao longo de toda a sua trajetória de vida para que se identifiquem como homens e mulheres, masculinos e femininos (MADUREIRA; BRANCO, 2007), capazes e com vontade de executar ou não determinadas atividades. É preciso trazer à superfície que o que está por trás de todo esse processo de construção é, antes de tudo, uma concepção de lugar, do lugar delineado e permitido ao homem e do lugar delineado e permitido à mulher dentro do cenário social.

Vale atentar para o fato de que algumas características são mais comumente relacionadas às mulheres e outras, aos homens, sendo fundamental lembrar que:

[...] toda e qualquer diferença é sempre atribuída no interior de uma dada cultura; que determinadas características podem ser valorizadas como distintivas e fundamentais numa determinada sociedade; e ainda, que a nomeação da diferença é, ao mesmo tempo e sempre, a demarcação de uma fronteira. (LOURO, 2012, p. 46).

Como características tradicionalmente atribuídas às mulheres podem ser citadas como exemplos aquelas que favorecem o ensino, o cuidado, as atividades domésticas cotidianas e a maternagem, como sensibilidade, passividade, meiguice, tolerância. Com relação às características tradicionalmente associadas aos homens podem ser citadas como exemplos as de liderança, agressividade, força física, lógica e ousadia. Vale dizer que:

[...] a expectativa de que mulheres sejam passivas por natureza e que homens sejam naturalmente agressivos é tão fortemente arraigada no imaginário do ocidente, que nem a ciência escapou a ela. Freud caracterizava a mulher como passiva, narcisista e masoquista. (WHITAKER, 1995, p. 37).

Nota-se ainda que as identidades, perspectivas e concepções de gênero na sociedade brasileira são construídas comumente a partir de estereótipos, o que limita a visão tanto de homens quanto de mulheres acerca de si mesmos e de suas potencialidades. E, apesar de atualmente não caber mais o apontamento de que as mulheres não estão preparadas ou não podem exercer determinadas atividades (NOGUEIRA, 2001) como, por exemplo, de liderança ou de que os homens não estão preparados para o cuidado das pessoas, percebe-se ainda uma 
prevalência de mulheres nos cursos relativos à educação e saúde enquadrados nas chamadas áreas de humanas e de biológicas, enquanto há um maior número de homens nos cursos enquadrados nas áreas de exatas (BRAGA; PEIXOTO; BOGUTCHI, 2001; BARDAGI; HUTZ, 2012; MELO, 2013).

Tem-se que essa realidade não pode ser explicada por um mero acaso ou simplesmente por questões de gosto, mas deve ser associada a uma educação formal e/ou informal, embora sempre sistematicamente diferenciada, que resulta, consequentemente, na produção de interesses, gostos, ideias, escolhas e possibilidades igualmente distintas. As identidades de gênero são construídas na e pela socialização das pessoas ao longo de toda a vida e são partes integrantes dessas últimas, bem como integram seus interesses e escolhas profissionais que também são gerados no processo de apropriação da cultura (MARTINS, 2011; MAIA et al, 2012).

Por tudo isso, a importância da reflexão e discussão das questões de gênero no tocante aos interesses e escolhas profissionais não pode ser minimizada nem tampouco deixada de lado, pois, com a manutenção da influência da construção dos papeis sociais de gênero em condição oculta, corre-se o risco de contribuir para a perpetuação histórica de discriminações e diferenciações entre homens e mulheres no âmbito social contemporâneo (FEIJÓ; MACEDO, 2012), o que inclui as relações de trabalho (GOULART JÚNIOR et al., 2013). E, por isso, faz-se tão necessário que meninas e meninos sejam igualmente "[...] preparados para percorrer novos caminhos com seu pensamento, para criticar e construir, para cozinhar e lavar pratos, para unificar o que foi fragmentado arbitrariamente" (MORENO, 1999, p. 12).

\section{Objetivos}

O presente artigo busca entender e discutir como a educação formal (escolar/acadêmica) e informal (família/amigos/mídia) que os indivíduos recebem, influencia os interesses e escolhas profissionais. Acredita-se que essa a educação seja sexista e, por isso, contribua significativamente para a (re)produção de lugares sociais diferentes para homens e mulheres a partir da atribuição de papeis sociais de gênero, levando a construção de diferentes formas de comportamentos e até mesmo de interesses e de escolhas.

\section{Método}


Para a elaboração deste artigo foram consultados os principais bancos de dados nacionais de Psicologia: o portal de periódicos eletrônicos de Psicologia (PePSIC) da Biblioteca Virtual em Saúde - Psicologia (BVS-PSI), Scientific Eletronic Library Online (SCIELO), bem como o banco de teses da Coordenação de Aperfeiçoamento de Pessoal de Nível Superior (CAPES) e os livros e periódicos catalogados na biblioteca da Universidade Estadual Paulista "Júlio de Mesquita Filho", campus de Bauru. A busca restringiu-se a estudos publicados entre os anos de 2009 e 2014 e foram usadas a palavras-chave "gênero" e "escolha profissional", o que resultou no acesso a um total de 77 artigos (dos quais foram selecionados 29 resultados), "gênero" e "interesses profissionais", que permitiu acessar 43 publicações (dos quais foram selecionados 27 resultados).

A seleção dos estudos encontrados foi realizada em três etapas. A primeira etapa consistiu em identificar quais artigos entendiam gênero como construção social, ou seja, não equivalente ao sexo biológico. A segunda etapa consistiu na seleção dos artigos, dentre os que entendiam gênero como construção social, que falavam da influência da educação na construção dos papéis sociais de gênero. A terceira etapa consistiu na divisão dos artigos, dentre os já selecionados, por temática principal, quais sejam: representações sociais de gênero (07 artigos), educação (07 artigos) e profissão (08 artigos). De acordo com os referidos critérios de inclusão, no final do processo de levantamento, foi selecionado o total de 22 publicações que foram utilizadas para embasar a discussão dos resultados.

\section{Resultados}

Conforme exposto, depois de realizado o levantamento dos estudos publicados entre os anos de 2009 e 2014 e com critérios de exclusão de artigos estabelecidos, realizou-se a categorização dos mesmos, de acordo com três temas principais: representação social de gênero, educação e profissão. A discussão dos resultados foi feita em consonância com a citada categorização.

No tema "representação social de gênero" foi alocado o total de 07 artigos, conforme demonstra a tabela 1 . 
Tabela 1: Representação social de gênero

\begin{tabular}{l|l|l}
\hline \multicolumn{1}{c|}{ Ano } & \multicolumn{1}{c}{ Autor } & \multicolumn{1}{c}{ Título } \\
\hline 2010 & SAAVEDRA, L. & \multicolumn{1}{c}{ Assimetrias de gênero nas escolhas vocacionais } \\
\hline 2010 & CHIES, P. & $\begin{array}{l}\text { Identidade de gênero e identidade profissional no campo } \\
\text { de trabalho }\end{array}$ \\
\hline 2010 & SILVA, S. S. da C. da et al. & $\begin{array}{l}\text { Rede social e papeis de gênero de casais ribeirinhos de } \\
\text { uma comunidade amazônica }\end{array}$ \\
\hline 2010 & FERTRIN, R. B. & $\begin{array}{l}\text { Mulheres em construção: o papel das mulheres } \\
\text { mutirantes na construção de casas populares }\end{array}$ \\
\hline 2010 & $\begin{array}{l}\text { MIGUEL, L. F.; } \\
\text { BIROLI, F. }\end{array}$ & $\begin{array}{l}\text { Práticas de gênero e carreiras políticas: vertentes } \\
\text { explicativas }\end{array}$ \\
\hline 2012 & $\begin{array}{l}\text { LAWLESS, Jennifer L.; FOX, Richard } \\
\text { L. }\end{array}$ & $\begin{array}{l}\text { Entrando na arena? Gênero e a decisão de concorrer a } \\
\text { um cargo eletivo }\end{array}$ \\
\hline 2013 & $\begin{array}{l}\text { NICOLAU, S. M.; SCHRAIBER, L. B.; } ; \\
\text { AYRES, J. R. de C. M. }\end{array}$ & $\begin{array}{l}\text { Mulheres com deficiência e sua dupla vulnerabilidade: } \\
\text { contribuições para a construção da integralidade em } \\
\text { saúde }\end{array}$ \\
\hline
\end{tabular}

Fonte: Elaboração própria.

A partir da leitura das citadas publicações, constatou-se que, em muitos casos, o gênero torna-se uma barreira e traz limitações bastante marcantes no processo de escolha profissional e no desenvolvimento de carreiras. Pode-se ver, ainda, que padrões de gênero são fatores importantes na delimitação de atividades cotidianas e na definição do status do lugar ocupado na organização familiar, condicionando a formação de vínculos sociais.

Ainda tratando sobre a representação social de gênero, coloca-se um exemplo de que, mesmo em um ramo marcado pela esmagadora presença masculina como o da construção civil, é possível acontecer uma mudança substancial nos papéis sociais exercidos pelas mulheres, passando as mesmas a ocupar posições de negociação e exercer trabalhos "pesados" e "perigosos" dentro da obra, construindo um novo sentido para o que é feminino (FERTRIN; VELHO, 2010).

Tratando especificamente da participação das mulheres na esfera política e a relação disso com as questões de gênero, tem-se que sua sub-representação pode ser explicada por três vertentes: o caráter patriarcal das instituições políticas liberais; os padrões culturais e de socialização que colocam o político como espaço masculino e inibem o desenvolvimento de interesse político entre as mulheres; e, por último, as especificidades estruturais da sociedade que fazem com que, em geral, as mulheres tenham menos recursos financeiros e muito menos tempo disponível para exercer essa atividade (MIGUEL; BIROLI, 2010).

Ainda considerando como foco a presença feminina na vida política, em diversos casos, as mulheres possuem as mesmas credenciais profissionais e habilidades pessoais que os homens para exercer determinados cargos públicos, mas não apresentam aquilo que é chamado de "ambição política" para tal. Essa falta de ambição pode ser explicada pelo fato de 
que as perspectivas de paridade de gênero nas instituições políticas norte-americanas são menos promissoras do que é apontado convencionalmente, devido a vestígios de uma socialização baseada em papéis sexuais tradicionais (MIGUEL; BIROLI, 2010).

Mudando o foco para a influência das representações sociais de gênero no tratamento de pessoas com deficiências, tem-se que o público feminino, apesar de numeroso, é alvo de ações inexpressivas dentro dos serviços de atenção básica em saúde; serviços estes que pouco reconhecem seus direitos sexuais e reprodutivos e que não são capazes de atentar-se para a dupla vulnerabilidade posta por sua condição de mulher com deficiência (NICOLAU; SCHRAIBER; AYRES, 2013).

No tocante ao tema "educação" foram selecionados 07 artigos, conforme demonstra a tabela 2.

Tabela 2: Educação

\begin{tabular}{c|l|l}
\hline \multicolumn{1}{c|}{ Ano } & \multicolumn{1}{c|}{ Autor } & \multicolumn{1}{c}{ Título } \\
\hline 2010 & POCINHO, M. D. et al & $\begin{array}{l}\text { Influência do gênero, da família e dos serviços de } \\
\text { psicologia e orientação na tomada de decisão de carreira }\end{array}$ \\
\hline 2010 & NEPOMUCENO, R F.; WITTER, G. P. & $\begin{array}{l}\text { Influência da família na decisão profissional: } \\
\text { Opinião de adolescentes }\end{array}$ \\
\hline 2011 & SIFUENTES, L.; RONSINI, V. & $\begin{array}{l}\text { O que a telenovela ensina sobre ser mulher? Reflexões } \\
\text { acerca das representações femininas }\end{array}$ \\
\hline 2011 & REIS, A. P. P. Z. dos; GOMES, C. A. & $\begin{array}{l}\text { Práticas pedagógicas reprodutoras de desigualdades: a } \\
\text { sub-representação de meninas entre alunos superdotados }\end{array}$ \\
\hline 2011 & RIBEIRO, C. M. & $\begin{array}{l}\text { Crianças, gênero e sexualidade: realidade e fantasia } \\
\text { possibilitando problematizações }\end{array}$ \\
\hline 2012 & ÀVILA, R. C.; P.; PORTES, E. A. & $\begin{array}{l}\text { A tríplice jornada de mulheres pobres na universidade } \\
\text { pública: trabalho doméstico, trabalho remunerado e } \\
\text { estudos }\end{array}$ \\
\hline 2013 & $\begin{array}{l}\text { MENEZES, A. B. de C.; BRITO, R. C. } \\
\text { S. }\end{array}$ & $\begin{array}{l}\text { Professores discriminados: um estudo sobre os docentes } \\
\text { do sexo masculino nas séries do ensino fundamental } \\
\text { brincadeiras de crianças na preferência de pares e }\end{array}$ \\
\hline
\end{tabular}

Fonte: Elaboração própria.

A partir da leitura das citadas publicações, contatou-se a existência de influência familiar, com relação à escolha profissional efetuada por adolescentes com idade acima de 16 anos provenientes de escolas públicas e privadas (POCINHO et al., 2010).

É possível concluir também que na área da docência, especificamente no trabalho com séries iniciais, os homens são negativamente afetados por representações de gênero geradoras de discriminação, uma vez que essa área é mais comumente ocupada por mulheres. Um dos estudos coloca que a simples presença de um professor na sala de aula pode provocar diferentes representações de gênero; e que este pode ou não trabalhar no sentido de desconstruir tais estereótipos (RABELO, 2013). 
Sobre os indicadores de educação, é possível perceber que, tanto no Brasil quanto na América Latina, a paridade de gênero da educação para todos é quase uma realidade. Entretanto, observando cada nicho pesquisado individualmente, fica evidente que, em alguns deles, as meninas ainda são tratadas de forma diferente, tratamento esse baseado em preconceitos e estereótipos, como é o caso do Programa de Atendimento ao Aluno com Altas Habilidades/Superdotação (REIS; GOMES, 2011).

Pode-se constatar também que, muitas vezes, o adulto exercita a violência de um olhar poderoso diante do desejo da criança, atravessando e impedindo que as questões de gênero e sexualidade possam ser esclarecidas e melhor vivenciadas. Entretanto, é importante ressaltar que também é possível que o adulto, intencionalmente, possibilite que a criança possa encharcar-se das temáticas de sexualidade e gênero (RIBEIRO, 2011).

Tratando-se da educação informal, tem-se que as telenovelas ajudam na constituição da identidade feminina de jovens mulheres de classe popular, reproduzindo um modelo feminino tradicional, mas, ao mesmo tempo, também dando indícios de uma representação de igualdade de gêneros - à qual as mesmas não têm acesso em sua vivência cotidiana (SIFUENTES; RONSINI, 2011). Por último, constatou-se que o dimorfismo sexual na preferência de pares e brincadeiras infantis, ainda que menos rígidos, é registrado desde muito cedo e, por isso, crianças com padrões atípicos do seu sexo tendem a apresentar dificuldades de socialização (MENEZES; BRITO, 2013).

No tema "profissão" foi alocado o total de 08 artigos, conforme demonstra a tabela 3.

Tabela 3: Profissão

\begin{tabular}{c|l|l}
\hline \multicolumn{1}{c|}{ Ano } & \multicolumn{1}{|c}{ Autor } & \multicolumn{1}{c}{ Título } \\
\hline 2010 & LOMBARDI, M. R. & $\begin{array}{l}\text { Profissão: Oficial engenheira naval da Marinha de } \\
\text { Guerra do Brasil }\end{array}$ \\
\hline 2010 & MADALOZZO, R.; et al. & $\begin{array}{l}\text { Participação no mercado de trabalho e no trabalho } \\
\text { domestico: homens e mulheres tem condições iguais? }\end{array}$ \\
\hline 2010 & RABELO, A. O. & $\begin{array}{l}\text { "Eu gosto de ser professor e gosto de crianças" - A } \\
\text { escolha profissional dos homens pela docência na escola } \\
\text { primária }\end{array}$ \\
\hline 2011 & DANIEL, C. & $\begin{array}{l}\text { Estranhamento, alienação e discriminação de gênero: O } \\
\text { trabalho da mulher professora }\end{array}$ \\
\hline 2011 & MADALOZZO, R. & $\begin{array}{l}\text { O trabalho e a questão de gênero: a participação de } \\
\text { mulheres na dinâmica do trabalho }\end{array}$ \\
\hline 2012 & SILVA, F. F.; RIBEIRO, P. R. C. & $\begin{array}{l}\text { CEOs e composição do conselho de administração: a } \\
\text { falta de identificação pode ser motivo para existência de } \\
\text { teto de vidro para mulheres no Brasil? }\end{array}$ \\
\hline 2012 & GRAF, L. P.; COUTINHO, M. C. & $\begin{array}{l}\text { A inserção das mulheres na ciência: narrativas de } \\
\text { mulheres cientistas sobre a escolha profissional }\end{array}$ \\
\hline
\end{tabular}

Fonte: Elaboração própria. 
A partir da leitura das citadas publicações, constatou-se que as engenheiras navais da Marinha convivem com uma realidade complexa, na qual as relações de gênero e de trabalho apresentam padrões de inserção e integração parecidos aos da engenharia não militar, ao mesmo tempo em que também possuem especificidades próprias (LOMBARDI, 2010).

Também é possível verificar que, em geral, as mulheres enfrentam uma dupla jornada de trabalho que se revela bastante pesada. Entretanto, sua participação no mercado de trabalho e o aumento de sua remuneração frente ao total da renda familiar têm impactado positivamente sua possibilidade de barganha e negociação dentro do núcleo familiar, resultando em certa redução na participação de algumas mulheres no serviço doméstico (MADALOZZO; MARTINS; SHIRATORI, 2010).

Assim como na categoria anterior, estudos relacionados à área de Profissão também investigam motivos de professores para a escolha de uma área tradicionalmente ocupada por mulheres. Nesse sentido, pode-se dizer que a escola reproduz a discriminação de gênero por meio de sua organização: em que a mulher, quase sempre, ocupa o lugar de professora e o homem, quando presente nessa área, aparece em cargos de coordenação e de supervisão cargos de maior visibilidade social. Essa estrutura legitima hierarquias sexistas e reproduz a formação da família tradicional que traz a mulher como mãe zelosa e cuidadora, e o homem como autoridade e liderança. Esses mesmos artigos destacam que a presença de professores do sexo masculino na área da docência já é uma forma de inserção das questões de gênero na educação, revelando que as capacidades para se exercer quaisquer profissões são independentes do sexo (RABELO, 2010).

Pode-se verificar, ainda, que o aumento da participação das mulheres no mercado do trabalho, apesar de um avanço, não possibilitou a superação das diferenças com relação aos salários e não promoveu a igualdade de tratamento nas promoções independente do gênero. Com relação à dificuldade de promoção encontrada por muitas mulheres, é possível afirmar que um dos fatores significativos de desigualdade é o fato de que os Conselhos de Administração das empresas buscam por candidatos que sejam a expressão máxima de seu próprio perfil de atuação. Sendo esses Conselhos compostos, esmagadoramente, pelo gênero masculino, os indivíduos femininos ainda sofrem uma maior resistência durante esse processo (MADALOZZO, 2011).

Por último, é possível compreender, por meio de alguns estudos, que a mulher tem se inserido em campos que anteriormente eram ocupados unicamente por homens, como é o caso da ciência e das pesquisas e como é o caso de trabalhos considerados mais "braçais" e "pesados", como abatedouros avícolas e construções civis (GRAF; COUTINHO, 2012). 
Apesar do avanço que essa inserção representa, a realidade cotidiana revela que dentro desses campos de trabalho as relações de gênero ainda se mostram bastante assimétricas, androcêntricas e sexistas, e que essas diferenças também podem ser observadas no ambiente familiar (SILVA; RIBEIRO, 2012).

\section{Discussão}

Os resultados indicam que as construções sociais acerca dos papeis de gênero, desenvolvidas ao longo da socialização dos indivíduos, contribuem para a manutenção da crença de que homens e mulheres são naturalmente diferentes um do outro e, dessa maneira, a eles cabe executar atividades apropriadas às características e habilidades próprias de seu gênero que são, por sua vez, consideradas inatas. Dessa maneira, o universo de possibilidades de homens e mulheres, mas, principalmente, de mulheres, permanece repleto de restrições que dificultam e/ou impedem que desenvolvam quaisquer profissões e planos de carreira e, quando o fazem, precisam transpor preconceitos e estereótipos (SIFUENTES; RONSINI, 2011; MADALOZZO, 2011; DANIEL, 2011).

Não se pode deixar de pontuar que se as construções acerca do que é do universo masculino e do que é do universo feminino são construídas socialmente, então, tudo se encontra ligado e permeado pela educação. É por meio dessa última que são transmitidas e aprendidas concepções de gênero, concepções de certo e errado, do que pode ou não ser sonhado, feito e alcançado por cada indivíduo (MORENO, 1999).

É por meio da educação que mulheres, desde tenra idade, são ensinadas que para serem plenamente felizes e modernas precisam ser mães e esposas dedicadas, donas de casa preparadas, com carreiras profissionais de sucesso, mas que permitam que elas tenham desenvoltura em todas as demais esferas. Enquanto os homens aprendem que, em primeiro lugar, devem ter carreiras profissionais de sucesso e, uma vez que o tenham, podem procurar cuidar, caso, assim, desejem, de outras esferas como relacionamentos amorosos, casamento e filhos.

Percebe-se, dessa maneira, que as construções sociais de gênero, o que inclui uma educação sexista, numa sociedade androcêntrica, de fato influenciam as escolhas profissionais tanto de homens quanto de mulheres. Assim, ainda que mulheres e homens, atualmente, cheguem a executar atividades laborais iguais, a condução de suas carreiras se dá de maneira diferente, com planos, promoções e cargos distintos, bem como com jornadas de trabalho fora 
e dentro do ambiente doméstico como uma realidade ainda predominantemente feminina (MORENO, 1999; MADALOZZO, 2011; ÁVILA; PORTES, 2012).

\section{Considerações finais}

Este texto, de atualização de literatura, privilegiou a discussão de estudos publicados que tratam dos papeis sociais de gênero a fim de verificar a influência que exercem sobre as escolhas e interesses profissionais. Depreende-se do levantamento realizado a existência de poucos estudos sobre a temática, evidenciando a necessidade e importância de novas pesquisas que viabilizem a reflexão e discussão das questões de gênero no tocante aos interesses e escolhas profissionais.

Acredita-se que o desenvolvimento da produção científica seja uma ferramenta fundamental para divulgação do tema aos profissionais da educação e dos campos sociais e de saúde, já que os mesmos podem contribuir significativamente para a diminuição de desigualdades e discriminações, vividas por homens e mulheres, em uma sociedade ainda androcêntrica e sexista.

Mudanças são necessárias e, especialmente nas escolas e famílias, educadores e cuidadores devem refletir sobre preconceitos de gênero; suas falas e comportamentos devem ajudar a desconstruir expectativas polarizadas no que diz respeito a gênero e estereótipos que permeiam relações e escolhas futuras de pessoas do sexo biológico masculino e feminino, pautadas em desigualdades. Algumas transformações vêm ocorrendo, mas enquanto as mulheres forem sobrecarregadas com a tripla carreira (trabalho externo, casa e filhos) e responsabilizadas pelo que falha no lar, ganharem menos, ocuparem menos cargos de liderança, haverá manutenção de desigualdade. Enquanto os meninos e as meninas não forem educados para a divisão de tarefas, para o respeito e colaboração, e as escolas estiverem mais preocupadas com conteúdos, vestibular e competitividade, a equidade estará distante. Vale lembrar que cada pessoa é uma e que a busca deve ser por equidade, ou seja, por equilíbrio de oportunidades.

A ampliação dos estudos na área pode contribuir para a compreensão dos processos de construção de papéis e de expectativas de gênero, o processo de atribuição de características e atributos femininos e masculinos, e de como tais atributos são socializados e apropriados pelos indivíduos durante a vida e relacionados a diversas profissões, originando crenças sobre a existência de profissões femininas e profissões masculinas, culminando em determinados interesses e escolhas profissionais em detrimento de outras. 


\section{REFERÊNCIAS}

AVILA, R. C.; PORTES, E. A. A tríplice jornada de mulheres pobres na universidade pública: trabalho doméstico, trabalho remunerado e estudos. Revista Estudos Feministas, Florianópolis, v.20, n.3, p.809-832, 2012.

BARDAGI. M. P.; HUTZ, C. S. Mercado de trabalho, desempenho acadêmico e o impacto sobre a satisfação universitária. Revista de Ciências Humanas, Florianópolis, v.46, n.1, p.183-198, 2012.

BELLUCCI, N. P. Estranhamento; alienação e discriminação de gênero: o trabalho da mulher professora. In: ENCONTRO BRASILEIRO DE EDUCAÇÃO E MARXISMO, 5., 2011, Florianópolis. Anais... Florianópolis: UFSC, 2011. Disponível em:

<http://www.5ebem.ufsc.br/trabalhos/eixo_03/e03f_t003.pdf>. Acesso em: 5 jun. 2014.

BOCK, S. D. Orientação profissional: a abordagem sócio-histórica. 3.ed. São Paulo: Cortez, 2006.

BORDO, S. R. O corpo e a reprodução da feminidade: uma apropriação feminista de Foucault. In: JAGGAR, A.; BORDO, S. R. Gênero, corpo e conhecimento. Tradução de Britta Lemos de Freitas. Rio de Janeiro: Record: Rosa dos Tempo. 1997. p.19-41. Disponível em: <https://crabgrass.riseup.net/assets/127594/versions/1/Jaggar,

$\% 20$ Alis $\% 20 \% 26 \% 20$ Bordo, $\% 2$

0Susan\%20G\%C3\%AAnero,\%20Corpo,\%20Sexualidade.pdf>. Acesso em: 10 jan. 2015.

BRAGA, M. M.; PEIXOTO, M. do C. L.; BOGUTCHI, T. F. Tendências da demanda pelo ensino superior: estudo de caso da UFMG. Cadernos de pesquisa, São Paulo, n.113, p.129152, jul. 2001. Disponível em: <http://www.scielo.br/pdf/cp/n113/a07n113.pdf>. Acesso em: 20 set. 2014.

CHIES, P. V. Identidade de gênero e identidade profissional no campo de trabalho. Revista Estudos Feministas, Florianópolis, v.18, n.2, p.507-528, 2010. Disponível em: <http://www.scielo.br/scielo.php?script=sci_arttext\&pid=S0104-026X2010000200013 >. Acesso em: 24 abr. 2014.

DANIEL, C. O trabalho e a questão de gênero: a participação de mulheres na dinâmica do trabalho. O social em questão, Rio de Janeiro, v.14, n.25/26, p.323-344, 2011. Disponível em: <http://osocialemquestao.ser.puc-rio.br/media/17_OSQ_25_26_Daniel.pdf〉. Acesso em: 13 maio 2014.

FEIJÓ, M. R.; MACEDO, R. M. Gênero, cultura e rede social - a construção social da desigualdade por meio da linguagem. Nova Perspectiva Sistêmica, Rio de Janeiro, n.44, p.21-34, 2012.

FERTRIN, R. B.; VELHO, L. M. L. Mulheres em construção: o papel mulheres mutirantes na construção de casas populares. Estudos Feministas, Florianópolis, v.18, n.2, p.585-606, 2010. Disponível em: <https://periodicos.ufsc.br/index.php/ ref/arti cle/view/S0104-026X210000200017/7/13760>. Acesso em: 1 dez. 2016. 
FOX, R. L.; LAWLESS, J. L. Entrando na arena? gênero e a decisão de concorrer a um cargo eletivo. Revista Brasileira de Ciência Política, Brasília, n.8, p.129-163, 2012. Disponível em: <http://www.scielo.br/pdf/rbcpol/n8/06.pdf>. Acesso em: 3 jun. 2014.

FURLANI, J. Educação sexual: possibilidades didáticas. In: LOURO, G. L.; FELIPE, J.; GOELLNER, S. V. (Org.). Corpo, gênero e sexualidade: um debate contemporâneo na educação. 8.ed. Petrópolis: Vozes, 2012. p.66-81.

GOULART JÚNIOR, E. et al. Exigências familiares e do trabalho: um equilíbrio necessário para a saúde de trabalhadores e organizações. Pensando famílias, Porto Alegre, v.17, n.1, jul. 2013. Disponível em: <http://pepsic.bvsalud.org/scielo.php?script=sci_arttext\& pid=S1679-494X2013000100011\&lng=pt\&nrm=iso >. Acesso em: 11 nov. 2014.

GRAF, L. P.; COUTINHO, M. C. Entre aves, carnes e embalagens: divisão sexual e sentidos do trabalho em abatedouro avícola. Revista Estudos Feministas, Florianópolis, v.20, n.3, p.761-783, 2012. Disponível em: 〈http://www.scielo.br/pdf/ref/v20n3/09.pdf>. Acesso em: 17 set. 2014.

LOMBARDI, M. R. Profissão: oficial engenheira naval da Marinha de Guerra do Brasil. Revista Estudos Feministas, Florianópolis, v.18, n.2, p.529-546, 2010. Disponível em: 〈http://www.scielo.br/pdf/ref/v18n2/14.pdf〉. Acesso em: 27 ago. 2014.

LOURO, G. L. Currículo, gênero e sexualidade - O "normal", o "diferente" e o "excêntrico". In: LOURO, G. L.; FELIPE, J; GOELLNER, S. V. (Org.). Corpo, gênero e sexualidade um debate contemporâneo na educação. 8.ed. Petrópolis: Vozes, 2012. p.41-52.

LOURO, G. L.; FELIPE, J.; GOELLNER, S. V. (Org.). Corpo, gênero e sexualidade - um debate contemporâneo na educação. 5.ed. Petrópolis: Vozes, 2010.

MADALOZZO, R. CEOs e composição do conselho de administração: a falta de identificação pode ser motivo para existência de teto de vidro para mulheres no Brasil?. Revista Administração Contemporânea, Curitiba, v.15, n.1, p.126-137, 2011. Disponível em: <http://www.scielo.br/pdf/rac/v15n1/v15n1a08.pdf>. Acesso em: 3 jun. 2014.

MADALOZZO, R.; MARTINS, S. R.; SHIRATORI, L. Participação no mercado de trabalho e no trabalho doméstico: homens e mulheres têm condições iguais? Revista Estudos Feministas, Florianópolis, v.18. n.2, p.547-566, 2010. Disponível em: <http://www.scielo.br/pdf/ref/v18n2/15.pdf>. Acesso em: 27 ago. 2014.

MADUREIRA, A. F. do A.; BRANCO, A. U. Identidades sexuais não-hegemônicas: processos identitários e estratégias para lidar com o preconceito. Psicologia: Teoria e Pesquisa, Brasília, v.23, n.1, p.81-90, 2007. Disponível em: <http://www.scielo.br/pdf/ptp/v23n1/a10v23n1.pdf>. Acesso em: 1 dez. 2010.

MAIA, A. C. B. et al. Educação sexual na escola a partir da psicologia histórico-cultural. Psicologia em Estudo, Maringá, v.17, n.1, p.151-156, jan./mar. 2012. Disponível em: $<$ http://www.scielo.br/scielo.php?script=sci_arttext\&pid=S1413-73722012000100017>. Acesso em: 1 dez. 2013. 
MARTINS, L. M. O desenvolvimento do psiquismo e a educação escolar: contribuições à luz da psicologia histórico cultural e da pedagogia histórico-crítica. 2011. 249f. Tese (LivreDocência em Psicologia) - Faculdade de Ciências, Universidade Estadual Paulista, Bauru, 2011.

MELO, M. C. M. Gênero e universidade: a presença da mulher aluna nos cursos do Centro de Ciências Exatas e Tecnologia da Universidade Federal do Maranhão. 2013. $106 f$.

Dissertação (Mestrado em Educação) - Universidade Federal do Maranhão, São Luís, 2013. Disponível em: <http://www.tedebc.ufma.br/tde_arquivos/11/TDE-2014-0116T103704Z835/Publico/DISSE RTACAO\%20MARIA\%20CELIA.pdf >. Acesso em: 10 ago. 2014.

MENEZES, A. B. de C.; BRITO, R. C. S. Diferenças de gênero na preferência de pares e brincadeiras de crianças. Psicologia: Reflexão e Crítica, Porto Alegre, v.26, n.1, p.193-201, 2013. Disponível em: <http://www.scielo.br/pdf/prc/v26n1/21.pdf>. Acesso em: 31 maio 2014.

MIGUEL, L. F.; BIROLI, F. Práticas de gênero e carreiras políticas: vertentes explicativas. Revista Estudos Feministas, Florianópolis, v.18, n.3, p.653-679, set./dez. 2010. Disponível em: 〈http://www.scielo.br/pdf/ref/v18n3/v18n3a03.pdf>. Acesso em: 31 maio 2014.

MORENO, M. Como se ensina a ser menina: o sexismo na escola. São Paulo: Moderna; Campinas: Ed. da Unicamp, 1999.

NEPOMUCENO, R. F.; WITTER, G. P. Influência da família na decisão profissional: opinião de adolescentes. Psicologia Escolar e Educional, São Paulo, v.14, n.1, p.15-22, 2010. Disponível em: <http://www.scielo.br/pdf/pee/v14n1/v14n1a02.pdf>. Acesso em: 31 maio 2014.

NICOLAU, S. M.; SCHRAIBER, L. B.; AYRES, J. R. de C. M. Mulheres com deficiência e sua dupla vulnerabilidade: contribuições para a construção da integralidade em saúde. Ciência \& Saúde Coletiva, Rio de Janeiro, v.18, n.3, mar. 2013. Disponível em: $<$ http://www.scielo.br/scielo.php?script=sci_arttext\&pid=S141381232013000300032\&lng=en\&nrm=iso>. Acesso em: 20 maio 2014.

NOGUEIRA, C. Questões de gênero na orientação vocacional - (re)construir novos discursos na prática. In: SEMINÁRIO "ORIENTAÇÃO ESCOLAR E PROFISSIONAL NA PROMOÇÃO DA IGUALDADE DE OPORTUNIDADES. 2001. Reconstruir os nossos olhares: o papel da orientação escolar e profissional na promoção da igualdade de oportunidades. Coimbra: ME- DREC, 2001. p.19-36. Disponível em: <https://repositorium.sdum.uminho.pt/bitstream/1822/4128/1/capitulo\%20quest\%C3\%B5es\% 20de\%20genero\%20na\%20orienta\%C3\%A7\%C3\%A3o\%20vocacional.pdf $>$. Acesso em: 15 abr. 2015.

POCINHO, M. D. et al. Influência do gênero, da família e dos serviços de psicologia e orientação na tomada de decisão de carreira. Revista Brasileira de Orientação Profissional, Florianópolis, v.11, n.2, p.201-212, 2010. Disponível em:

<http://pepsic.bvsalud.org/pdf/rbop/v11n2/v11n2a05.pdf>. Acesso em: 17 abr. 2014. 
PRAUN, A. G. Sexualidade, gênero e suas relações de poder. Revista Húmus, São Luís, v.1, n.1, p.55-65, 2011. Disponível em:

<http://www.periodicoseletronicos.ufma.br/index.php/revistahumus/article/view/1641/1302>. Acesso em: 25 mar. 2014.

RABELO, A. O. Professores discriminados: um estudo sobre os docentes do sexo masculino nas séries do ensino fundamental. Educação e Pesquisa, São Paulo, v.39, n.4, p.907-925, 2013. Disponível em: <http://www.scielo.br/pdf/ep/v39n4/aop1132.pdf>. Acesso em: 17 abr. 2014.

RABELO, A. O. "Eu gosto de ser professor e gosto de crianças" - a escolha profissional dos homens pela docência na escola primária. Revista Lusófona de Educação, Lisboa, n.15, p.163-173, 2010. Disponível em: <http://www.scielo.oces.mctes.pt/pdf/rle/n15/n15a12>. Acesso em: 17 abr. 2014.

REIS, A. P. Z. dos; GOMES, C. A. Práticas pedagógicas reprodutoras de desigualdades: a sub-representação de meninas entre alunos superdotados. Revista Estudos Feministas, Florianópolis, v.19, n.2, p.503-520, 2011. Disponível em: <http://www.scielo.br/pdf/ref/v19n2/v19n2a13.pdf>. Acesso em: 5 jun. 2014.

RIBEIRO, C. M. Crianças, gênero e sexualidade: realidade e fantasia possibilitando problematizações. Revista Estudos Feministas, Florianópolis, v.19, n.2, p.605-614, 2011. Disponível em: <http://www.scielo.br/pdf/ref/v19n2/v19n2a20.pdf >. Acesso em: 5 jun. 2014.

SAAVEDRA, L. Assimetrias de género nas escolhas vocacionais. In: PINTO, T. (Coord.). Guião de Educação Género e Cidadania: $3^{\circ}$ ciclo do ensino básico. Lisboa: Comissão para a cidadania e igualdade de género, 2009. p.121-129.

SANTOS, L. M. O papel da família e dos pares na escolha profissional. Psicologia em Estudo, Maringá, v.10, n.1, p.57-66, jan./abr. 2005. Disponível em: <http://www.scielo.br/pdf/pe/v10n1/v10n1a07.pdf >. Acesso em: 15 abr. 2015.

SIFUENTES, L.; RONSINI, V. O que a telenovela ensina sobre ser mulher? reflexões acerca das representações femininas. Revista Famecos, Porto Alegre, v.18. p.131-146, 2011. Disponível em: $<$ http://revistaseletronicas.pucrs.br/ojs/index.php/revistafamecos/article/view/8802>. Acesso em: 31 maio 2014.

SILVA, F. F.; RIBEIRO, P. R. C. A inserção das mulheres na ciência: narrativas de mulheres cientistas sobre a escolha profissional. Linhas Críticas (UnB), Brasília, v.18, p.171-191, 2012. Disponível em: < http://periodicos.unb.br/index.php/linhascriticas/arti cle/view/6830>. Acesso em: 31 maio 2014.

SILVA, S. S. da C. et al. Rede social e papéis de gênero de casais ribeirinhos de uma comunidade amazônica. Psicologia: Teoria e Pesquisa, Brasília, v.26, n.4, p.605-612, 2010. Disponível em: <http://www.scielo.br/scielo.php?pid=S010237722010000400004\&script=sci_arttext $>$. Acesso em: 4 jun. 2014. 
WHITAKER, D. C. A. Menino-menina - sexo ou gênero? alguns aspectos cruciais. In: BINO, R. V.; GRANDE, M. A. R. L. (Org.). A escola e seus alunos: o problema da diversidade cultural. São Paulo: Ed. da UNESP, 1995. p.31-52.

\section{Como referenciar este artigo}

LIMA, Flaviane Izidro Alves de.; et al. A influência da construção de papeis sociais de gênero na escolha profissional. Doxa: Rev. Bras. Psicol. Educ., Araraquara, v.19, n.1, p. 33-50, jan./ jun. 2017. ISSN: 1413-2060.

Submetido em: 10/01/2017

Aprovado em: 28/03/2017 